\title{
Current advances in molecular subtyping using multilocus variable number of tandem repeat analysis of Salmonella Enteritidis and Salmonella Typhimurium in Egyptian chickens
}

\author{
Wafaa M. M. Hassan ${ }^{1}$ (D), Ashraf A. Abd El Tawab² ${ }^{\mathbb{D}}$ and Sara M. El-Shannat ${ }^{3}$ (D) \\ 1. Reference Laboratory for Quality Control on Poultry Production, Animal Health Research Institute, Dokki, Giza, Egypt; \\ 2. Department of Bacteriology, Immunology, and Mycology, Faculty of Veterinary Medicine, Benha University, Benha, \\ Egypt; 3. Department of Microbiology, Animal Health Research Institute, Marsa Matruh, Egypt. \\ Corresponding author: Sara M. El-Shannat, e-mail: saramvet@yahoo.com \\ Co-authors: WMMH: fooaaa@live.com, AAAE: ashrafabdeltwab@yahoo.com \\ Received: 08-06-2020, Accepted: 21-09-2020, Published online: 28-10-2020
}

doi: www.doi.org/10.14202/vetworld.2020.2252-2259 How to cite this article: Hassan WMM, El Tawab AAA, El-Shannat SM (2020) Current advances in molecular subtyping using multilocus variable number of tandem repeat analysis of Salmonella Enteritidis and Salmonella Typhimurium in Egyptian chickens, Veterinary World, 13(10): 2252-2259.

\begin{abstract}
Aim: This study aimed to characterize the genetic diversity, evolutionary level, and prevalence of genotypes of common isolates of Salmonella (Salmonella Enteritidis and Salmonella Typhimurium). Using one of the most advanced molecular recognition techniques, multilocus variable number of tandem repeat analysis (MLVA), we characterized the genotype and prevalence of $S$. Enteritidis and $S$. Typhimurium.

Materials and Methods: One hundred and twenty-five internal organ samples were collected from the major chicken slaughterhouses in Egypt, and Salmonella species were isolated. PCR was utilized to amplify the $I E-1$ and Flic-C genes to identify $S$. Enteritidis and $S$. Typhimurium DNA, respectively, from Salmonella isolates. MLVA was applied on nine samples of $S$. Enteritidis DNA and three samples of $S$. Typhimurium DNA. Six variable number tandem repeat (VNTR) loci (Sal02, Sal04, Sal06, Sal10, Sal20, and Sal23) were amplified.

Results: Of the examined samples $(\mathrm{n}=125)$, a total of 12 isolates $(9.6 \%)$ were either identified as Enteritidis or Typhimurium. PCR-mediated amplification of $I E-1$ and Flic-C revealed that $75 \%(\mathrm{n}=9)$ of the 12 Salmonella isolates were $S$. Enteritidis and $25 \%(\mathrm{n}=3)$ were $S$. Typhimurium. The six loci amplified through MLVA had allelic diversity. The most discriminatory heterogenic locus for $S$. Enteritidis was Sal20. Sal04 and Sal23 were the most discriminatory heterogenic loci for $S$. Typhimurium. VNTR allelic profile analysis revealed nine unique genotypes for $S$. Enteritidis and three for $S$. Typhimurium.

Conclusion: This study was the first to use MLVA analysis to identify $S$. Enteritidis and $S$. Typhimurium strains isolated from chickens in Egypt. The molecular typing data reported herein allowed us to characterize the genotypes of $S$. Enteritidis and $S$. Typhimurium that are most prevalent in Egyptian chickens. Moreover, this epidemiological information provides valuable insight on how to prevent disease transmission. Moreover, our methods provide an alternative to traditional serotyping techniques that may produce inaccurate strain identifications for organisms with rough lipopolysaccharide structures.
\end{abstract}

Keywords: lipopolysaccharides, multilocus variable number of tandem repeat analysis, Salmonella, serotyping.

\section{Introduction}

Salmonella enterica serotypes Enteritidis and Typhimurium are two of the most famous zoonotic strains of Salmonella worldwide [1]. The serotype Salmonella Enteritidis possesses one of the most prominent risks for severe economic danger in Europe and many countries throughout the world [2]. The serotype Typhimurium is considered a major cause of human and animal salmonellosis [3]. A multi-country outbreak of $S$. Enteritidis confirmed through whole-genome sequencing (WGS) analysis is currently ongoing. There are currently 314 confirmed

Copyright: Hassan, et al. Open Access. This article is distributed under the terms of the Creative Commons Attribution 4.0 International License (http://creativecommons.org/licenses/ by/4.0/), which permits unrestricted use, distribution, and reproduction in any medium, provided you give appropriate credit to the original author(s) and the source, provide a link to the Creative Commons license, and indicate if changes were made. The Creative Commons Public Domain Dedication waiver (http:// creativecommons.org/publicdomain/zero/1.0/) applies to the data made available in this article, unless otherwise stated. cases in Austria, France, Ireland, Luxembourg, and the United Kingdom. Besides, Austria, Belgium, Denmark, the Netherlands, Norway, and the United Kingdom reported collectively 21 probable and 50 historical probable cases. Confirmed cases belong to three closely related genetic clusters. Possible cases have been related to the multilocus variable number tandem repeat (VNTR) multilocus variable number of tandem repeat analysis (MLVA) profiles 2-11-3-3-2 and 2-12-3-3-2. However, 1 additional confirmed isolate has an MLVA profile of 2-9-3-3-2 [4].

Poultry and poultry byproducts are serious vehicles in infection transmission to consumers [5]. Moreover, chickens infected with $S$. Enteritidis play a role in infection spread through trans-ovarian transmission during the stage of egg development [6]. Most reported cases of $S$. Typhimurium infection are also related to infected food products; few cases are reported as a result of direct contact with infected animals or contaminated water or environment $[7,8]$. 
Due to a lack of distinctive genotype properties between $S$. Enteritidis and $S$. Typhimurium isolate, it is possible that they have evolved from the same ancestor clone. Determining an accurate clone is complicated by the fact that the Salmonella species is not asexual and the final end product of recombination replacement can result in a large number of highly diverse genotypes under the same clonal complex. The clonal diversity of bacteria varies according to the extent of recombination that can vary depending on bacterial species [9]. As MLVA and WGS are not utilized in all EU/EEA countries, other European Union countries may be inadvertently affected by this outbreak. This underscores the need for the use of MLVA analysis to identify comorbidities related to the ongoing outbreak. Performing WGS analysis on isolates associated with the outbreak on MLVA profiles would further confirm their participation in the ongoing outbreak [4].

In Egypt, there is a lack of genetic-relatedness data collected from $S$. Enteritidis and $S$. Typhimurium isolated from chickens. It is imperative to use highly advanced molecular subtyping techniques such as MLVA, to accurately identify strains with rough lipopolysaccharide structures.

A combination of MLVA with other molecular techniques, such as pulsed-field gel electrophoresis (PFGE), ribotyping, and phage typing, provide clear data that can accurately identify the outbreak strain and distinguish it from epidemiologically unrelated isolates [10-12].

The three methods previously noted have been proven incompetent in Salmonella typing when not used in conjunction with techniques such as MLVA. Many reports demonstrate that PFGE is considered insufficient as a tool for molecular typing of Salmonella species, mainly due to poor reproducibility in different aboratories. Ribotyping also has low discrimination power and is not useful in the current epidemiological investigation and surveillance study of the ongoing outbreak [13-16]. The use of phage typing is not ideal because it revealed that some $S$. Enteritidis strains could not be typed due to phage conversion among strains [17].

For these reasons, MLVA is considered the current method of choice for genotyping $S$. enterica ( $S$. Enteritidis and $S$. Typhimurium) in most laboratories. MLVA is fast, highly reproducible, cost-effective, can be used with small amounts of DNA, can discriminate between clinical isolates, and allows for systematic analysis as it opens a way for data standardization through processing and development of web-based resources for database query $[18,19]$. MLVA analyzes the variation in the numbers of tandem repeated sequences in DNA at multiple genomic loci [20]. This means that each target region is individually amplified using specific primers that anneal to the flanks of the repeat-containing region. Determination of the amplicon sizes by electrophoresis on agarose gels enables the number of tandem repeat units present at each locus to be deduced [21-23].
The application of the MLVA technique using Interspersed Repetitive Units-Variable Number of Tandem Repeats for the identification of $S$. Enteritidis and $S$. Typhimurium strains isolated from chickens provides accurate data to appropriately identify outbreak strains and distinguish them from epidemiologically unrelated isolates. Furthermore, the MLVA technique can help in determining the prevalence of different Salmonella genotypes.

This study aimed to characterize the genetic diversity, evolutionary level, and genotype prevalence of the most predominant isolates of Salmonella ( $S$. Enteritidis and $S$. Typhimurium) in Egyptian chickens. Using the advanced MLVA technique allowed us to decipher the genotypes and spread of $S$. Enteritidis and $S$. Typhimurium in Egypt.

\section{Materials and Methods}

\section{Ethical approval}

No ethical approval was needed to perform this study. However, the samples were treated according to the national and international criteria.

\section{Sampling}

One hundred and twenty-five random samples from broiler chickens tissues (internal organs) were collected from different slaughterhouses in Egypt for examination, in the period from December 2017 to October 2019.

The samples were collected following the protocol recommended by the International Commission on Microbiological Specification for Food [24]. The samples were transported on ice to the reference laboratory for quality control on poultry production (Animal Health Research Institute, Dokki, Giza, Egypt). The samples were sealed in sterile bags and stored at $-86^{\circ} \mathrm{C}$.

\section{Bacteriological examination}

The samples were treated according to the method described by standard ISO 6579:2002 [25] and CDC manual [26].

\section{Isolation of Salmonella species from chicken tissue samples}

In brief, $5 \mathrm{~g}$ of tissue samples, which included intestine, liver, kidney, heart, and spleen, were thawed at room temperature under aseptic conditions. The samples were then macerated into fine pieces using sterile blades, homogenized using a sterile pestle and mortar, added to $45 \mathrm{~mL}$ of buffered peptone water (HiMedia, India), and then incubated at $37^{\circ} \mathrm{C}$ for $18 \mathrm{~h}$. After the incubation, either $0.1 \mathrm{~mL}$ or $1 \mathrm{~mL}$ of pre-enriched aliquots were transferred into $10 \mathrm{~mL}$ Rappaport and vassiliadis broth for the enrichment and incubated at $42^{\circ} \mathrm{C}$ for $24 \mathrm{~h}$ (HiMedia, India). Finally, the enriched aliquot samples were seeded on MacConkey and xylose-lysine-deoxycholate (XLD) agar [27] and incubated at $37^{\circ} \mathrm{C}$ for $24-48 \mathrm{~h}$ for the observation of the growth of typical Salmonella colonies (HiMedia, India), (i.e., pink colonies with a black center on XLD plates and colorless colonies on MacConkey plates). 


\section{Extraction of Salmonella genomic DNA}

Genomic DNA was obtained from Salmonella subcultures from XLD (HiMedia, India), plates according to manufacturer's instructions from the QIAamp Blood and Tissue Kit for Gram-Negative Bacteria (Qiagen ${ }^{\circledR}$, Hilden, Germany). Briefly, colonies (2-3) were harvested in a microcentrifuge tube by centrifuging for $10 \mathrm{~min}$ at $5000 \times g(7500 \mathrm{rpm})$. Supernatants were subsequently discarded and the remaining pellet was resuspended in $180 \mu \mathrm{L}$ buffer ATL. $20 \mu \mathrm{L}$ of proteinase $\mathrm{K}$ was added and the mixture was incubated for $2 \mathrm{~h}$ at $56^{\circ} \mathrm{C}$ to allow for extensive bacterial lysis. DNA was eluted from the QIAamp mini spin columns with $100 \mu \mathrm{L}$ of buffer to increase the concentration of the recovered DNA. The concentration of DNA was measured using UV absorption with a spectrophotometer (BMG Labtech, Germany) at a wavelength of $260 \mathrm{~nm}$. The DNA was stored at $-20^{\circ} \mathrm{C}$ for further analysis.

Molecular identification of $S$. Enteritidis and S. Typhimurium DNA based on IE-1 and Flic- $\boldsymbol{C}$ genes

PCR was used to amplify the $I E-1$ and Flic-C genes, which are specific for $S$. Enteritidis and $S$. Typhimurium, respectively. A 316- and 432-bp fragment containing $I E-1$ and Flic- $C$ gene sequences was amplified by PCR. Primers specific for $I E-1$ were: $I E-1 / \mathrm{F}\left(5^{\prime}-\right.$ AGT GCC ATA CTT TTA ATG AC -3') and $I E-1 / \mathrm{R}\left(5^{\prime}\right.$ - ACT ATG TCG ATA CGG TGG G -3'). Primers for Flic-C were: Flic-C/F (5'- CCC GCT TAC AGG TGG ACT AC -3) and Flic-C/R ('5'- AGC GGG TTT TCG GTG GTT GT-3). These primers have been found to be specific and more reliable for the differentiation of $S$. Typhimurium from other members of the Salmonella species [28]. DNA samples were subjected to two differential amplification reactions in two separate tubes. The $S$. Enteritidis specific amplification reaction mixtures were identical to those of $S$. Typhimurium with the exception of the primers targeting $I E-1$ instead of Flic-C. PCR reactions were carried out in $25 \mu \mathrm{L}$ containing $5 \mu \mathrm{L}$ of $5 \times$ PCR master mix (Jena bioscience $\AA$, Germany), $3 \mu$ L of each primer (forward and reverse) at a working concentration of $10 \mathrm{pmol} / \mu \mathrm{L}$, (Metabion International AG®, Germany)
$2 \mu \mathrm{L}$ of DNA template, and $12 \mu \mathrm{L}$ ddH2O. For $M T B C$ identification, the primer set $I E-1 / \mathrm{F}, I E-1 / \mathrm{R}$, and Flic-C/F, Flic-C/R was used according to the following parameters: Initial denaturation at $95^{\circ} \mathrm{C}$ for $5 \mathrm{~min}$, followed by 30 cycles at $95^{\circ} \mathrm{C}$ for $1 \mathrm{~min}$, annealing at $58^{\circ} \mathrm{C}$ for $1 \mathrm{~min}$, extension at $72^{\circ} \mathrm{C}$ for $30 \mathrm{~s}$, and a final extension at $72^{\circ} \mathrm{C}$ for $7 \mathrm{~min}$ [29]. The amplification products were resolved by electrophoresis on a $1.5 \%$ agarose gel, followed by ethidium bromide staining $(0.5 \mu \mathrm{g} / \mathrm{mL})$ and examination under UV light.

\section{MLVA}

Literature was extensively reviewed to identify primer sequences for $S$. enterica loci with potential to distinguish $S$. Enteritidis and $S$. Typhimurium strains. Six polymorphic tandem repeat loci, which vary in size from 107 to $250 \mathrm{bp}$, were expected to have potential to distinguish the two serovars [30]. In this study for MLVA analysis, six VNTR (0681, 0764, 0789, 2053, 4301, and 4774) primer pairs were used (Table-1) [31]. The PCR reaction was performed in a total volume of $25 \mu \mathrm{L}$ per reaction with the following reagent concentrations: $5 \mu \mathrm{L}$ of $5 \times$ PCR master mix (Jena bioscience ${ }^{\circledR}$, Germany), $3 \mu \mathrm{L}$ of each primer (forward and reverse) at a working concentration of $10 \mathrm{pmol} / \mu \mathrm{L}$, (Metabion International AG®, Germany) $12 \mu \mathrm{L}$ ddH2O, and $2 \mu \mathrm{L}$ of genomic DNA as a template. PCR was conducted (Biometra, Germany) with the following cycling parameters: Initial denaturation at $96^{\circ} \mathrm{C}$ for $5 \mathrm{~min}$, followed by 30 cycles at $96^{\circ} \mathrm{C}$ for $30 \mathrm{~s}$, annealing at $62^{\circ} \mathrm{C}$ for $1 \mathrm{~min}$, extension at $72^{\circ} \mathrm{C}$ for $1 \mathrm{~min}$, and final extension at $72^{\circ} \mathrm{C}$ for $10 \mathrm{~min}$. Positive and negative controls were included in each set of reactions and consisted of the same reaction mixtures with genomic DNA of $S$. Enteritidis and $S$. Typhimurium reference strains as the template for the positive control and no template DNA in the negative control. The PCR fragments were analyzed by gel electrophoresis using 2\% agarose stained with ethidium bromide for each locus. Sizes of amplicons were estimated by comparison with $50 \mathrm{bp}$ markers (Jena bioscience $\mathbb{R}$, Germany), and the number of repetitive units was determined. The genomic sequences of $S$. Enteritidis and S. Typhimurium (ATCC 13076 and

Table-1: Primer sequences and the size of the repeat units of the VNTR loci in this study.

\begin{tabular}{|c|c|c|c|}
\hline VNTR locus & VNTR locus alias & VNTR locus size (bp) & PCR Primer sequences $\left(5^{\prime}-3^{\prime}\right)$ \\
\hline 0681 & Sal 02 & 6 & $\begin{array}{l}\text { (F) GGA AAG ACT GGC GAA CAA AT } \\
\text { (R) TCG CCA ATA CCA TGA GTA CG }\end{array}$ \\
\hline 0764 & Sal 04 & 20 & $\begin{array}{l}\text { (F) TCG CAC AGA TGA CCA ATT TT } \\
\text { (R) GAT CGA CGC TCA CTG CTT C }\end{array}$ \\
\hline 0789 & Sal 06 & 6 & $\begin{array}{l}\text { (F) TTGGTCGCGGAACTATAACTG } \\
\text { (R) CTTCGTCTGATTGCCACTCC }\end{array}$ \\
\hline 2053 & Sal 10 & 12 & $\begin{array}{l}\text { (F) AAGCGACGTTCTTCTGCAAC } \\
\text { (R) TGGAATATGATGGCATGACG }\end{array}$ \\
\hline 4301 & Sal 20 & 3 & $\begin{array}{l}\text { (F) CAGCCGACACAACTTAACGA } \\
\text { (R) ACTGTACCGTGCGCGTTT }\end{array}$ \\
\hline 4774 & Sal 23 & 12 & $\begin{array}{l}\text { (F) CCCGCACACTAAGGAGAGAC } \\
\text { (R) ACCGCGTTAGTGGCTAACAT }\end{array}$ \\
\hline
\end{tabular}

List of primers used for $S$. Enteritidis and S. Typhimurium strains typing obtained from [31]. A total of six loci were selected for amplification of DNA from Salmonella isolates 
Table-2: Description of each VNTR locus, repeat unit size, flank size, tandem repeat copy number, number of alleles, and fragments length size.

\begin{tabular}{|c|c|c|c|c|c|c|c|c|c|}
\hline \multirow[t]{2}{*}{ Locus } & \multirow[t]{2}{*}{$\begin{array}{l}\text { Repeat unit } \\
\text { size (bp) }\end{array}$} & \multicolumn{2}{|c|}{$\begin{array}{l}\text { No. of } \\
\text { alleles }\end{array}$} & \multicolumn{2}{|c|}{$\begin{array}{c}\text { Tandem repeat coy } \\
\text { number }\end{array}$} & \multicolumn{2}{|c|}{ Fragment length (bp) } & \multirow[t]{2}{*}{$\begin{array}{c}\text { Flank size } \\
\text { (bp) }\end{array}$} & \multirow{2}{*}{$\begin{array}{c}\text { Description of each } \\
\text { VNTR locus" }\end{array}$} \\
\hline & & SE & $\mathrm{Tm}$ & SE & Tm & SE & Tm & & \\
\hline Sal 02 & 6 & 4 & 2 & $1,2,3,4$ & 4,5 & $\begin{array}{c}95,101,107 \\
113\end{array}$ & 113,119 & 89 & $\begin{array}{c}(6 \times 1)+89,(6 \times 2)+89 \ldots \\
\text { etc. }\end{array}$ \\
\hline Sal 04 & 20 & 3 & 3 & $1,2,3$ & $1,2,3$ & $174,194,214$ & $\begin{array}{c}174 \\
194,214\end{array}$ & 154 & $\begin{array}{c}(20 \times 1)+154 \\
(20 \times 2)+154 \ldots \text { etc. }\end{array}$ \\
\hline Sal 06 & 6 & 2 & 2 & 2,3 & 5,6 & 156,162 & 174,180 & 144 & $(6 \times 2)+144,(6 \times 3)+144$ \\
\hline Sal 10 & 12 & 3 & 2 & $1,2,3$ & 3,4 & $184,196,208$ & 208,220 & 172 & $\begin{array}{c}(12 \times 1)+172 \\
(12 \times 2)+174 \ldots . \text { etc. }\end{array}$ \\
\hline Sal 20 & 3 & 6 & 2 & $\begin{array}{c}8,10,11,12 \\
13,14\end{array}$ & 16,17 & $\begin{array}{c}169,175,178 \\
181,184,187\end{array}$ & 193,196 & 145 & $\begin{array}{c}(3 \times 8)+145 \\
(3 \times 10)+145 \ldots \text { etc. }\end{array}$ \\
\hline Sal 23 & 12 & 3 & 3 & $3,4,5$ & $4,5,6$ & $250,262,274$ & $\begin{array}{c}264 \\
274,285\end{array}$ & 214 & $\begin{array}{c}(12 \times 3)+214 \\
(12 \times 4)+214 \ldots \text { etc. }\end{array}$ \\
\hline
\end{tabular}

"Each VNTR locus was described as (repeat unit sizexcopy number) + size of the partial repeat. SE=Salmonella Enteritidis, Tm=Salmonella Typhimurium

ATCC 14028, respectively) were also used as reference strains and were evaluated to obtain the amplicon sequence for each locus [32].

\section{Determination of tandem repeats}

The number of tandem repeats in each amplified MLVA locus was estimated based on the amplified MLVA loci size and the size of the flanking region using the formula in Table-2.

PCR assays for the six loci were repeated and compared within and between gels to ensure consistent estimation of size and tandem repeat copy number.

\section{Results}

PCR-mediated detection of $S$. Enteritidis and $S$. Typhimurium DNA from isolates based on the presence of $I E-1$ and Flic-C genes 12 Salmonella isolates ( $9.6 \%$ of the samples collected) were identified in this study. All DNA extracted from bacterial isolates was subjected to PCR amplification of target sequences specific for $S$. Enteritidis $(I E-1)$ and $S$. Typhimurium (Flic-C) (Figure-1). PCR based IE-1 gene and Flic-C identification for Salmonella isolates revealed that 9/12 of the Salmonella isolates were $S$. Enteritidis and 3/12 were $S$. Typhimurium (Table-3).

\section{Genotyping of $S$. Enteritidis and $S$. Typhimurium using MLVA}

MLVA was applied to 12 samples of Salmonella DNA which was classified into two groups. Based on the amplification of the six VNTR loci, the first group consisted of nine samples which were classified as $S$. Enteritidis and the second group consisted of three samples that were classified as $S$. Typhimurium. These six polymorphic loci identified 12 unique MLVA genotypes (Table-4). Nine unique genotypes were specific to $S$. Enteritidis (A, B, C, D, E, F, G, H, and I) while three unique genotypes ( $\mathrm{J}, \mathrm{K}$, and $\mathrm{L}$ ) were specific to $S$. Typhimurium.

Data for all six loci $(0681,0764,0789,2053$, 4301, and 4774) were found to be polymorphic in both $S$. Enteritidis and $S$. Typhimurium DNA. A representative agarose gel is shown in Figures-2 and 3. All MLVA
Table-3: Results of PCR-based IE-1 sequences and allelespecific Flic-C gene method versus culture on MacConkey and XLD agar.

\begin{tabular}{|c|c|c|c|c|}
\hline \multirow[t]{2}{*}{$\begin{array}{l}\text { Isolate } \\
\text { No. }\end{array}$} & \multicolumn{2}{|c|}{ Culture media } & \multicolumn{2}{|c|}{$\begin{array}{c}\text { DNA from } \\
\text { Salmonella isolates }\end{array}$} \\
\hline & $\begin{array}{c}\text { MacConkey } \\
\text { agar }\end{array}$ & $\begin{array}{l}\text { XLD } \\
\text { agar }\end{array}$ & $I E-1$ & Flic-C \\
\hline 1 & + ve & + ve & + ve & $-v e$ \\
\hline 2 & + ve & + ve & + ve & $-v e$ \\
\hline 3 & + ve & + ve & $+\mathrm{ve}$ & $-v e$ \\
\hline 4 & $+v e$ & + ve & $+\mathrm{ve}$ & $-v e$ \\
\hline 5 & $+v e$ & + ve & $+\mathrm{ve}$ & $-v e$ \\
\hline 6 & + ve & + ve & $+\mathrm{ve}$ & $-v e$ \\
\hline 7 & $+\mathrm{ve}$ & + ve & $+\mathrm{ve}$ & $-v e$ \\
\hline 8 & + ve & +ve & + ve & $-v e$ \\
\hline 9 & +ve & + ve & + ve & $-v e$ \\
\hline 10 & + ve & + ve & $-v e$ & + ve \\
\hline 11 & + ve & + ve & $-v e$ & + ve \\
\hline 12 & + ve & + ve & $-v e$ & $+v e$ \\
\hline
\end{tabular}

types were comprised single isolates with unique genotypes (Table-4) and yielded the results (Table-2), we expected based on a previous report [31]. The length of the yielded amplicon in bp must be calculated as number of repeats (Table-2).

\section{Discussion}

In recent decades, the $S$. enterica serovars enteritidis and Typhimurium have been considered the main source of outbreaks in Egyptian poultry farms [33]. The use of effective and accurate molecular typing techniques has significantly benefited epidemiological studies. To prevent and detect potential outbreaks, further exploration of transmission methods is necessary. For this purpose, MLVA was recently introduced in Egyptian laboratories to investigate outbreaks of both $S$. Enteritidis and $S$. Typhimurium serovars. However, some economical and technical obstacles, including economic instability, higher cost of advanced molecular genotyping techniques, and the lack of adequate laboratory equipment for of characterization of $S$. Enteritidis and $S$. Typhimurium, prevent widespread use of MLVA in Egypt. 
This study documented the occurrence of $S$. Enteritidis and $S$. Typhimurium in Egyptian chickens. The findings are of public health concern, especially in the realm of poultry farming. The results revealed that $75 \%$ of the isolates submitted for PCR

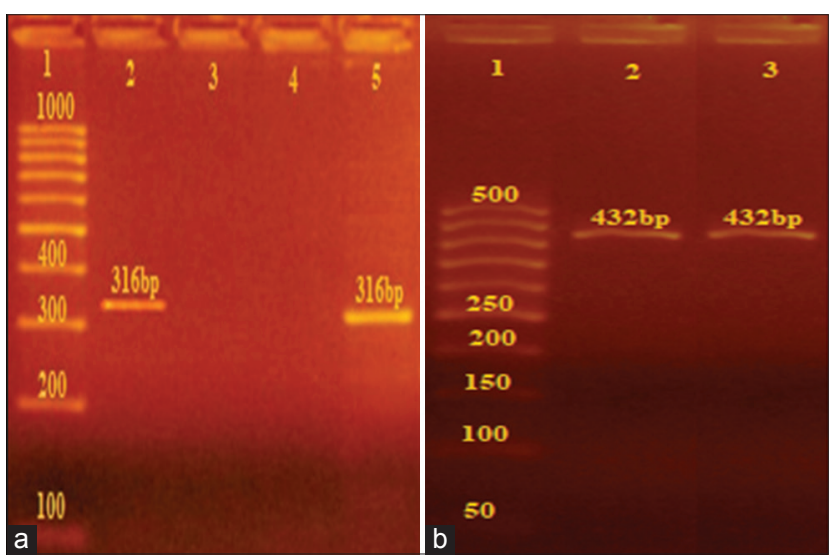

Figure-1: PCR- identification of Salmonella Enteritidis and Salmonella Typhimurium DNA based IE-1 sequences and allele-specific Flic-C gene. (a) DNA extraction from Salmonella isolate. Amplicons obtained with IE-1 (lanes 2, 5) with the size of $316 \mathrm{bp}$. Lanel: 100 base pair ladder, (Jena bio science ${ }^{\circledR}$ ). (b) DNA extraction from Salmonella isolate. Amplicons obtained with Flic-C (lanes 2, 3) with the size of 432 bp. Lanel: 50 base pair ladder, (Jena bio science $\left.{ }^{\circledR}\right)$. analysis were $S$. Enteritidis while the remaining $25 \%$ were $S$. Typhimurium. The serovars were distinguished through the amplification of two distinct primer sets. The enteritidis specific primer (IE-1) was reported previously $[31,34]$. The Typhimurium specific primer (Flic-C) amplified a gene that participates in flagellin synthesis and was chosen from a whole-genome sequence database for the $S$. Typhimurium strain AY649720 retrieved from GenBank [29,35]. The specificity of primer pairs was confirmed using the BLAST algorithm at NCBI (http://www.ncbi.nlm. nih.gov). The results of PCR amplification showed sharp bands of a 316-bp fragment (diagnostic for $S$. Enteritidis) and a 432-bp fragment (diagnostic for $S$. Typhimurium).

MLVA was assessed as a molecular tool for genotyping 12 samples of Salmonella DNA. Of those 12 samples, nine samples were $S$. Enteritidis and three were $S$. Typhimurium. DNA was extracted from isolates based on traditional epidemiological tracing information using six VNTR markers. These markers comprised Sal02, Sal04, Sal06, Sal10, Sal20, and Sal23 from a previously reported MLVA scheme developed for $S$. enterica [30].

There were 12 unique MLVA genotypes (A, B, C, D, E, F, G, H, and I) that represented $S$. Enteritidis.

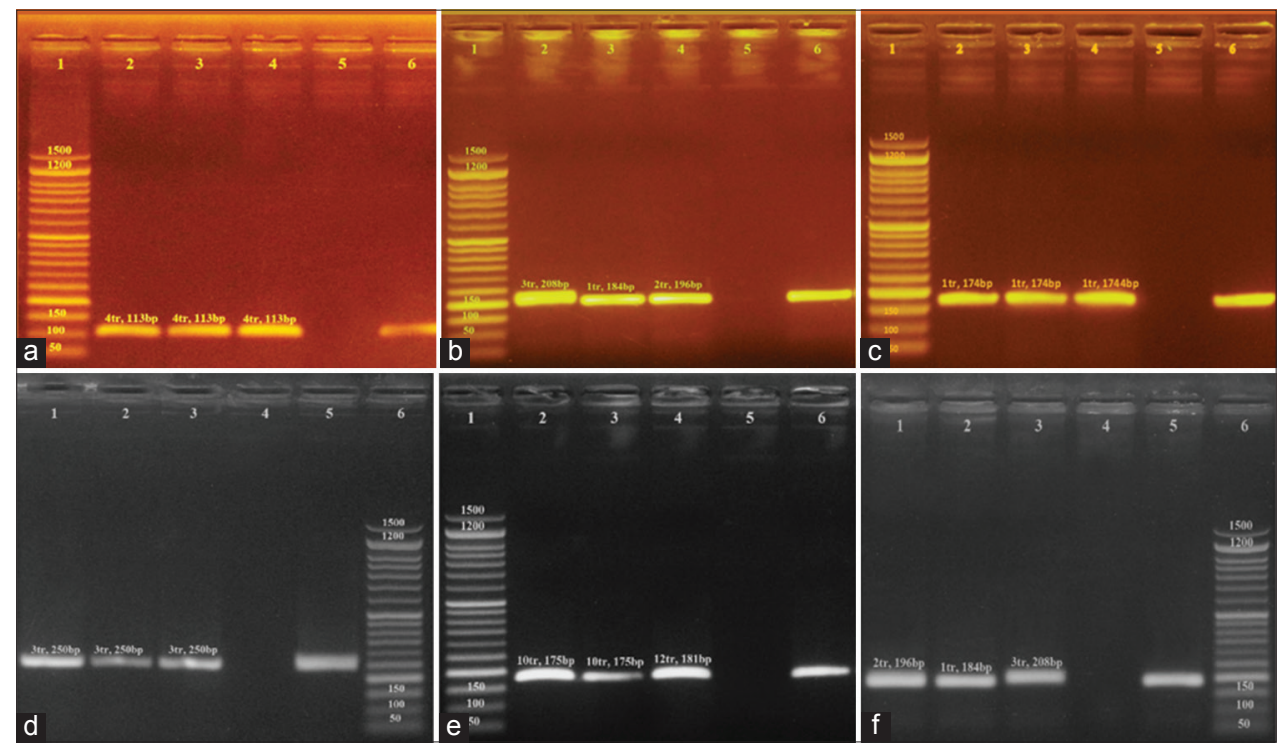

Figure-2: The results of multilocus variable number of tandem repeat analysis typing, based on DNA extracted from grown Salmonella Enteritidis isolates. (a) MLVA typing of DNA from grown S. enteritides isolates using the 0681 locus (Lane 2, 3, and 4), with a tandem repeat size of 6 base pairs. Lanel: 50 base pair ladder; Lane 2, 3 and 4: Amplicon obtained based on 0681 locus with fragment length of $113 \mathrm{bp}$ (4tr); Lane 5, and 6: negative and positive control respectively. (b) MLVA typing of DNA from grown S. enteritides isolates using the 2053 locus (Lane 2, 3, and 4), with a tandem repeat size of 12 base pairs. Lane1: 50 base pair ladder; Lane 2, 3 and 4: Amplicon obtained based on 2053 locus with fragment length of 208 bp respectively; Lane 5, and 6: negative and positive control respectively. (c) MLVA typing of DNA from grown S. enteritides isolates using the 0764 locus (Lane 2, 3, and 4), with a tandem repeat size of 20 base pairs. Lanel: 50 base pair ladder; Lane 2, 3 and 4: Amplicon obtained based on 0764 locus with fragment length of $174 \mathrm{bp}$ (1tr); Lane 5, and 6: negative and positive control respectively. (d) MLVA typing of DNA from grown S. enteritides isolates using the 4774 locus (Lane 2, 3, and 4), with a tandem repeat size of 12 base pairs. Lane6: 50 base pair ladder; Lane 1, 2, and 3: Amplicon obtained based on 4774 locus with fragment length of $250 \mathrm{bp}$ (3tr) ; Lane 4, and 5: negative and positive control respectively. (e) MLVA typing of DNA from grown S. enteritides isolates using the 4301 locus (Lane 2, 3, and 4), with a tandem repeat size of 3 base pairs. Lane 1: 50 base pair ladder; Lane 2, 3 and 4: Amplicon obtained based on 4301 locus with fragment length of 175 bp (10tr), 175 (10tr), and $181 \mathrm{bp}$ (12tr) respectively; Lane 5, and 6: negative and positive control respectively. (f) MLVA typing of DNA from grown S. ententides isolates using the 2053 locus (Lane 1, 2, and 3), with a tandem repeat size of 12 base pairs. Lane 6: 50 base pair ladder; Lane 1, 2 and 3: Amplicon obtained based on 2053 locus with fragment length of 196 bp (2tr), 184 bp (1tr), and 208 bp (3tr) respectively; Lane 4, and 5: negative and positive control respectively. 


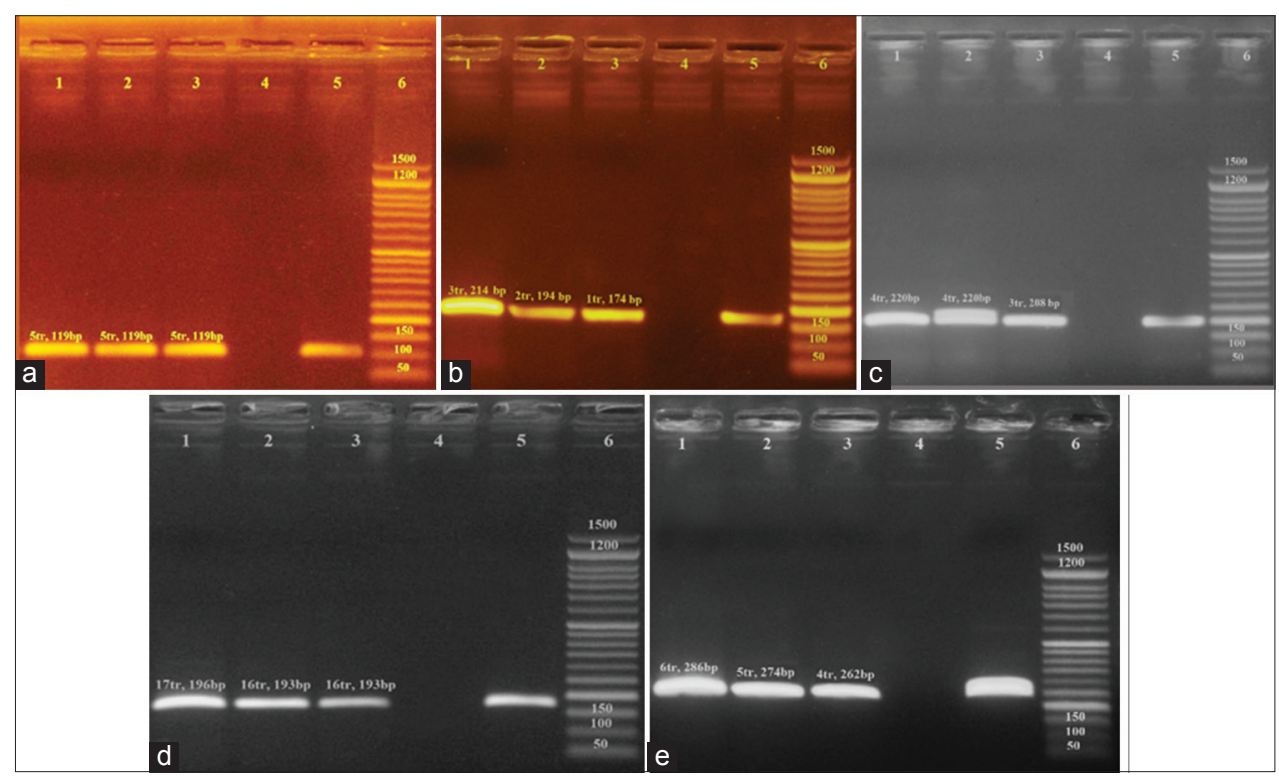

Figure-3: The results of multilocus variable number of tandem repeat analysis typing, based on DNA extracted from grown Salmonella Typhimurium isolates. (a) MLVA typing of DNA from grown S. typhimurium isolates using the 0681 locus (Lane 1,2 , and 3), with a tandem repeat size of 6 base pairs. Lane 6: 50 base pair ladder; Lane 1, 2 and 3: Amplicon obtained based on 0681 locus with fragment length of $119 \mathrm{bp}$ (5tr) Lane 4, and 5: negative and positive control respectively. (b) MLVA typing of DNA from grown S. typhimurium isolates using the 0764 locus (Lane 1, 2, and 3), with a tandem repeat size of 20 base pair 6: 50 base pair ladder; Lane 1, 2 and 3: Amplicon obtained based on 0764 locus with fragment length of $214 \mathrm{bp}$ (3tr), $194 \mathrm{bp}$ (2tr), and $174 \mathrm{bp}$ (1tr) respectively; Lane 4, and 5: negative and positive control respectively. (c) MLVA typing of DNA from grown $S$. typhimurium isolates using the 2053 locus (Lane 1, 2, and 3), with a tandem repeat size of 12 base pairs. Lane 6: 50 base pair ladder; Lane 1, 2 and 3: Amplicon obtained based on 2053 locus with fragment length of $220 \mathrm{bp}$ (4tr), $220 \mathrm{bp}$ (4tr), and $208 \mathrm{bp}$ (3tr) respectively; Lane 4, and 5: negative and positive control respectively. (d) MLVA typing of DNA from grown S. typhimurium isolates using the 4301 locus (Lane 1, 2, and 3), with a tandem repeat size of 3 base pairs. Lane 6: 50 base pair ladder; Lane 1,2 and 3: Amplicon obtained based on 4301 locus with fragment length of $196 \mathrm{bp}$ (17tr), $193 \mathrm{bp}$ (16tr) and $193 \mathrm{bp}$ (16tr) respectively; Lane 4, and 5: negative and positive control respectively. (e) MLVA typing of DNA from grown S. typhimurium isolates using the 4774 locus (Lane 1, 2, and 3), with a tandem repeat size of 12 base pairs. Lane 6: 50 base pair ladder; Lane 1, 2 and 3: Amplicon obtained based on 4774 locus with fragment length of 286 bp (6tr), 274 bp (5tr), and 262 bp (4tr) respectively; Lane 4, and 5: negative and positive control respectively.

Table-4: The VNTR allelic profiles of the S. Enteritidis and S. Typhimurium in Egypt.

\begin{tabular}{|c|c|c|c|c|c|c|c|c|c|c|c|c|c|c|}
\hline \multirow[t]{2}{*}{ Locus } & \multicolumn{12}{|c|}{$\begin{array}{l}\text { VNTR copy number for six polymorphic loci ( } 12 \text { unique } \\
\text { multilocus variable number of tandem repeat analysis type A-L) }\end{array}$} & \multicolumn{2}{|c|}{ Tandem repeat copy number/locus } \\
\hline & A & B & $\mathbf{C}$ & $\mathbf{D}$ & $\mathbf{E}$ & $\mathbf{F}$ & $\mathbf{G}$ & $\mathbf{H}$ & $\mathbf{I}$ & J & $\mathbf{K}$ & $\mathbf{L}$ & S. Enteritidis & S. Typhimurium \\
\hline 0681 & 1 & 2 & 2 & 3 & 3 & 4 & 4 & 4 & 4 & 5 & 4 & 5 & $1,2,3,4$ & 4,5 \\
\hline 0764 & 1 & 1 & 1 & 1 & 1 & 1 & 2 & 3 & 3 & 3 & 2 & 1 & $1,2,3$ & $1,2,3$ \\
\hline 0789 & 2 & 3 & 3 & 2 & 2 & 2 & 2 & 3 & 3 & 5 & 5 & 6 & 2,3 & 5,6 \\
\hline 2053 & 1 & 1 & 1 & 2 & 1 & 3 & 3 & 1 & 2 & 4 & 4 & 3 & $1,2,3$ & 3,4 \\
\hline 4301 & 12 & 14 & 13 & 12 & 12 & 11 & 10 & 8 & 12 & 17 & 16 & 16 & $8,10,11,12,13,14$ & 16,17 \\
\hline 4774 & 3 & 3 & 3 & 4 & 4 & 3 & 4 & 5 & 5 & 6 & 5 & 4 & $3,4,5$ & $4,5,6$ \\
\hline
\end{tabular}

S. Enteritidis=Salmonella Enteritidis, $S$. Typhimurium=Salmonella Typhimurium, VNTR=Variable number tandem repeat

Alternatively, three unique genotypes ( $\mathrm{J}, \mathrm{K}$, and L) represented $S$. Typhimurium. Tyhpimurium and Enteritidis genotypes were dispersed throughout the region of study area.

All six loci had polymorphisms in both $S$. Enteritidis and $S$. Typhimurium. The analysis of $S$. Enteritidis DNA revealed that five loci $(0681,0764$, 0789,2053 , and 4774 ) were involved in only a 1-step change in TR copy number. The locus 4301 did exhibit a change in TR copy number, which varied from 8 to 14 copies with a 1- or 2-step change in the TR copy number. $S$. Typhimurium had a 1-step change only in the TR copy number in all loci examined.
This data could not be compared with other Egyptian studies as there have been no previous studies on the genotypes of $S$. Enteritidis and $S$. Typhimurium in Egypt. However, our results are similar to those reported from $S$. enterica isolated from blood and stool samples from symptomatic patients in France [30]. In the French study, loci Sal04, Sa106, Sal10, Sal20, and Sal23 showed higher diversity in tandem repeat copy number than in our study. Notably, there was a complete difference in the tandem repeat copy number of Sal 02. Another study based on the typing of Heidelberg isolates [36] revealed that tandem repeat copy numbers for Sa102, 
Sal10, and Sal20 are similar to our reported results for $S$. Enteritidis. This suggests the possibility that not all Sal loci are informative for the identification of $S$. enterica serovars. Therefore, the formation of a locus standardization model for each serovar is an urgent necessity. The data from molecular typing have allowed us to discern the genotypes of $S$. Enteritidis and $S$. Typhimurium that are prevalent in Egyptian chickens. Moreover, this epidemiological information gives us insight into how to prevent disease transmission of salmonellosis [37].

\section{Conclusion}

MLVA typing is an effective and beneficial tool for investigating and identifying early warning signs of Salmonella outbreaks and providing epidemiological surveillance for $S$. Enteritidis and $S$. Typhimurium infections.

\section{Authors' Contributions}

SME created the research and experimental design, performed the laboratory experiment, data analysis, and wrote the manuscript. AAAE supervised the experiment, checked the data analysis, and revised the manuscript. WMMH supervised the experiment, helped in the laboratory work, and revised the manuscript. All authors contributed to drafting and revision of the manuscript. All authors read and approved the final manuscript.

\section{Acknowledgments}

The authors are thankful to Reference Laboratory for Quality Control on Poultry Production, Animal Health Research Institute, Dokki, Giza, Egypt, for providing the necessary laboratory facilities for this study. The authors did not receive any funds for this research.

\section{Competing Interests} interests.

The authors declare that they have no competing

\section{Publisher's Note}

Veterinary World remains neutral with regard to jurisdictional claims in published institutional affiliation.

\section{References}

1. González, F. and Araque, M. (2019) Molecular typing, antibiotic resistance profiles and biocide susceptibility in Salmonella enterica serotypes isolated from raw chicken meat marketed in Venezuela. Germs, 9(2): 81-88.

2. Sher, A.A. (2018) Spatial and Temporal Analysis of Salmonella Enteritidis Outbreaks in USA, 1990-2015. Michigan State University, United States.

3. Dar, M.A., Urwat, U., Ahmad, S.M., Ahmad, R., Kashoo, Z.A., Dar, T.A. and Heidari, M. (2019) Gene expression and antibody response in chicken against Salmonella Typhimurium challenge. Poult. Sci., 98(5): 2008-2013.

4. European Centre for Disease Prevention and Control. (2017) Multi-country outbreak of Salmonella Enteritidis 2-11-3-3-2 and 2-12-3-3-2. European Centre for Disease
Prevention and Control, Stockholm.

5. Luvsansharav, U.O., Vieira, A., Bennett, S., Huang, J., Healy, J.M., Hoekstra, R.M. and Cole, D. (2020) Salmonella serotypes: A novel measure of association with foodborne transmission. Foodborne Pathog. Dis., 17(2): 151-155.

6. Pande, V.V., Devon, R.L., Sharma, P., McWhorter, A.R. and Chousalkar, K.K. (2016) Study of Salmonella Typhimurium infection in laying hens. Front. Microbiol., 7: 203.

7. Lambertini, E., Buchanan, R.L., Narrod, C. and Pradhan, A.K. (2016) Transmission of zoonotic bacterial pathogens between pets and humans: The role of pet food. Crit. Rev. Food Sci. Nutr., 56(3): 364-418.

8. Bondo, K.J., Pearl, D.L., Janecko, N., Boerlin, P., ReidSmith, R.J., Parmley, J. and Jardine, C.M. (2016) Impact of season, demographic and environmental factors on Salmonella occurrence in raccoons (Procyon lotor) from swine farms and conservation areas in Southern Ontario. PLoS One, 11(9): e0161497.

9. Saeed, A.M., Walk, S.T., Arshad, M. and Whittam, T.S. (2006) Clonal structure and variation in virulence of Salmonella Enteritidis isolated from mice, chickens, and humans. J. AOAC Int., 89(2): 504-511.

10. Hauer, A., Michelet, L., Cochard, T., Branger, M., Nunez, J., Boschiroli, M.L. and Biet, F. (2019) Accurate phylogenetic relationships among Mycobacterium bovis strains circulating in France based on whole-genome sequencing and single nucleotide polymorphism analysis. Front. Microbiol., 10: 955.

11. Nsofor, C.A. (2016) Pulsed-field gel electrophoresis (PFGE): Principles and applications in molecular epidemiology: A review. Int. J. Curr. Res. Med. Sci., 2(2): 38-51.

12. Liebana, E., Garcia-Migura, L., Breslin, M.F., Davies, R.H. and Woodward, M.J. (2001) Diversity of strains of Salmonella enterica serotype Enteritidis from English poultry farms assessed by multiple genetic fingerprinting. $J$. Clin. Microbiol., 39(1): 154-161.

13. Tau, N.P., Smith, A.M., Wain, J.R., Tarupiwa, A., Coulibaly, K.J. and Keddy, K.H. (2017) Development and evaluation of a multiple-locus variable-number tandem-repeats analysis assay for subtyping Salmonella Typhi strains from Sub-Saharan Africa. J. Med. Microbiol., 66(7): 937-945.

14. Crabb, H.K., Allen, J.L., Devlin, J.M., Firestone, S.M., Stevenson, M., Wilks, C.R. and Gilkerson, J.R. (2019) Traditional Salmonella Typhimurium typing tools (phage typing and MLVA) are sufficient to resolve well-defined outbreak events only. Food Microbiol., 84: 103237.

15. Liao, J., Orsi, R.H., Carroll, L.M., Kovac, J., Ou, H., Zhang, H. and Wiedmann, M. (2019) Serotype-specific evolutionary patterns of antimicrobial-resistant Salmonella enterica. BMC Evol. Biol., 19(1): 132.

16. Riley, L.W. (2004) Molecular Epidemiology of Infectious Diseases: Principles and Practices. American Society for Microbiology, Washington, DC, United States.

17. Gast, R.K. and Porter, R.E. Jr., (2020) Salmonella infections. In: Diseases of Poultry. John Wiley and Sons, Hoboken, New Jersey. p717-753.

18. Maiden, M.C., Bygraves, J.A., Feil, E., Morelli, G., Russell, J.E., Urwin, R. and Feavers, I. (1998) Multilocus sequence typing: A portable approach to the identification of clones within populations of pathogenic microorganisms. Proc. Natl. Acad. Sci. U. S. A., 95(6): 3140-3145.

19. Liu, Y., Lee, M.A., Ooi, E.E., Mavis, Y., Tan, A.L. and Quek, H.H. (2003) Molecular typing of Salmonella enterica serovar Typhi isolates from various countries in Asia by a multiplex PCR assay on variable-number tandem repeats. J. Clin. Microbiol., 41(9): 4388-4394.

20. Tang, S., Orsi, R.H., Luo, H., Ge, C., Zhang, G., Baker, R.C. and Wiedmann, M. (2019) Assessment and comparison of molecular subtyping and characterization methods for Salmonella. Front. Microbiol., 10(2019): 1591.

21. International Commission on Microbiological Specifications for Foods. (2011) Microorganisms in Food 8. Springer Science, Heidelberg, Germany. 
22. International Organization for Standardization. (2002) Microbiology-General Guidance on Methods for the Detection of Salmonella. International Organization for Standardization, Geneva, Switzerland.

23. Bakuła, Z., Brzostek, A., Borówka, P., Żaczek, A., SzulcKiełbik, I., Podpora, A. and Bielecki, J. (2018) Molecular typing of Mycobacterium kansasii using pulsed-field gel electrophoresis and a newly designed variable-number tandem repeat analysis. Sci. Rep., 8(1): 1-11.

24. United States Department of Agriculture. (2007) Salmonella, Listeria, and Campylobacter on U.S. Dairy Operations, 1996-2007. United States Department of Agriculture, Washington, DC, United States.

25. Wang, S. and Yeh, D. (2002) Designing of polymerase chain reaction primers for the detection of Salmonella Enteritidis in foods and faecal samples. Lett. Appl. Microbiol., 34(6): 422-427.

26. Paião, F.G., Arisitides, L.G., Murate, L.S., Vilas-Bôas, G.T., Vilas-Boas, L.A. and Shimokomaki, M. (2013) Detection of Salmonella spp, Salmonella Enteritidis and Typhimurium in naturally infected broiler chickens by a multiplex PCRbased assay. Braz. J. Microbiol., 44(1): 37-42.

27. Rozen, S. and Skaletsky, H. (2000) Primer3 on the www for general users and for biologist programmers. In: Bioinformatics Methods and Protocols, Humana Press, Totowa, NJ. p365-386.

28. Le Flèche, P., Fabre, M., Denoeud, F., Koeck, J.L. and Vergnaud, G. (2002) High resolution, on-line identification of strains from the Mycobacterium tuberculosis complex based on tandem repeat typing. BMC Microbiol., 2(1): 37.

29. Silva, D.S., Canato, T., Magnani, M., Alves, J., Hirooka, E.Y. and Oliveira, T.C. (2011) Multiplex PCR for the simultaneous detection of Salmonella spp. and Salmonella Enteritidis in food. Int. J. Food Sci. Technol., 46(7): 1502-1507.

30. Soumet, C., Ermel, G., Rose, V., Rose, N., Drouin, P.,
Salvat, G. and Colin, P. (1999) Identification by a multiplex PCR-based assay of Salmonella Typhimurium and Salmonella Enteritidis strains from environmental swabs of poultry houses. Lett. Appl. Microbiol., 29(1): 1-6.

31. Ramisse, V., Houssu, P., Hernandez, E., Denoeud, F., Hilaire, V. and Vergnaud, G. (2004) Variable number of tandem repeats in Salmonella enterica subsp. enterica for typing purposes. J. Clin. Microbiol., 42(12): 5722-5730.

32. Young, C.C. (2013) Molecular Typing of Salmonella enterica Serovars of Significance in Australia Using MLVA and Bacteriophage Genes. Doctoral Dissertation. The University of Adelaide, Adelaide, Australia.

33. Jajere, S.M. (2019) A review of Salmonella enterica with particular focus on the pathogenicity and virulence factors, host specificity and antimicrobial resistance including multidrug resistance. Vet. World, 12(4): 504

34. Skuce, R.A., McCorry, T.P., McCarroll, J.F., Roring, S.M., Scott, A.N., Brittain, D. and Neill, S.D. (2002) Discrimination of Mycobacterium tuberculosis complex bacteria using novel VNTR-PCR targets. Microbiol., 148(2): 519-528.

35. Supply, P., Mazars, E., Lesjean, S., Vincent, V., Gicquel, B. and Locht, C. (2000) Variable human minisatellite-like regions in the Mycobacterium tuberculosis genome. Mol. Microbiol., 36(3): 762-771.

36. Allix, C., Walravens, K., Saegerman, C., Godfroid, J., Supply, P. and Fauville-Dufaux, M. (2006) Evaluation of the epidemiological relevance of variable-number tandem-repeat genotyping of Mycobacterium bovis and comparison of the method with IS6110 restriction fragment length polymorphism analysis and spoligotyping. J. Clin. Microbiol., 44(6): 1951-1962.

37. Abd El-Ghany, W.A., El-Shafii, S.S. and Hatem, M.E. (2012) A survey on Salmonella species isolated from chicken flocks in Egypt. Asian J. Anim. Vet. Adv., 7(6): 489-501. 